\title{
Writing Anxiety and the Use of Subordinate Clauses in the Written Compositions of Jordanian EFL Undergraduate Students
}

\author{
Maram Teimeh Atallah Haddad \\ Department of English, Irbid University College, Al-Balqa Applied University, Jordan
}

\begin{abstract}
The present study aimed to explore the correlation between writing anxiety and the an aspect of the grammatical complexity of Jordanian EFL students' written compositions, i.e. the use of subordinate clauses. Eighty seven students, who were purposefully chosen from among the freshmen and senior students at AlBalqa Applied University participated in the study. Writing Anxiety Inventory (WAI) was used in order to collect the data during the first semester of the academic year 2017/ 2018. The findings of the study showed statistically significant differences between the mean scores of the freshmen and senior students in both the levels of writing anxiety and the number of subordinate clauses used in written compositions, in favor of the group of senior students. In addition, a significant correlation was found between the level of writing anxiety and the grammatical complexity of the written compositions of the participants of the study, as reflected in their use of subordinate clauses. Pedagogical implications and suggestions for further research are presented.
\end{abstract}

Index Terms - writing anxiety, subordinate clauses, written compositions, undergraduate students

\section{INTRODUCTION}

During their years of study at the university, EFL students are frequently asked to demonstrate their knowledge through writing. Yet, a large number of students have difficulty composing text at a level required by the curriculum.

Daly and Miller introduced the concept of writing anxiety, also called writing apprehension in 1975. The term "writing apprehension" describes a writing-specific anxiety, which can be defined as a situation and subject specific individual difference that is associated with the tendencies of an individual to approach or avoid the situation which entails writing accompanied with a degree of perceived evaluation (Daly \& Miller, 1975, 242-249).

Recent studies revealed significant negative correlations between ESL writing anxiety and writing performance. For instance, students with low levels of anxiety do not only write better quality compositions, but also write more than their counterparts with higher levels of anxiety. Writing under time constraints was also found to be a detrimental effect of writing anxiety (Al-Shimi, 2017). Cheng (2004) found a significant negative correlation between anxiety and performance of EFL students in writing tasks. The impacts of writing anxiety on the writing processes and behaviors of EFL students consist of cognitive interference in writing process, feelings of nervousness or tension, and avoidance of writing (Cheng, 2004).

Syntactic (i.e., grammatical) complexity, is a concept which is considered as an essential construct of language proficiency, which has been explored extensively in the field of second language (L2) writing, delineates the level of sophistication of the forms that appear in language production. Syntactic complexity is a multidimensional concept, and is measured and evaluated through a variety of methods that explore the different dimensions of the construct. The number of clauses per written text, is one of the widely used measures of complexity, such capture a relative degree of sophistication (Park, 2017).

Subordination is an essential component in making sentences in any language, and it refers to a way of combining clauses so as to make one part of it more important than the other(s). from the perspective of Linguistics, subordination is defined as a complex syntactic construction in which one or more clauses are dependent on the main clause (Adjei \& Williams, 2014).

Subordinate clause ratios have been used as a measure of linguistic complexity, and they appeared among the most valid indicators of proficiency among L2 learners because they areconsidered as consistently linear and influenced by program or school level (Baten \& Håkansson, 2015).

Generalizations concerning the constructs of fluency, accuracy and complexity, which were derived from research on the development of writing skill in L2, include the following: 1) learners yield more lengthy and complicated texts within a certain time frame as they become more proficient in writing in L2, 2).fewer mistakes appear in their texts, and 3)the sentences they produce in their L2 written texts become more complex, both grammatically and lexically. Complexity in writing is divided into grammatical and lexical complexity. Grammatical complexity in its turn can be divided into grammatical variation and sophistication. Several quantifiable measures that assess the proficiency level among L2 students have been employed in research, such as the number and types of subordinate clauses which appear 
in written compositions, and the amount of complex noun phrases. Thus, various studies have examined grammatical complexity in written text production (Larsen, 2016).

Zhang (2011) found that EFL students, especially those who employ productive skills such as speaking and writing, frequently feel anxious in the learning process (Zhang, 2011).

\section{LITERATURE REVIEW}

Saeedi and Farnia (2017) examined the association between English as a foreign language (EFL) learners' ratings of their writing anxiety and the quality of their task-based written production in terms of complexity, accuracy, and fluency. To this aim, 45 Iranian high-intermediate EFL learners were asked to complete the Second Language Writing Anxiety Inventory (SLWAI) (Cheng, 2004) in order to rate their perceived level of anxiety while writing in English. In addition, to elicit samples of their written production, they were required to perform the narrative task of writing down a story based on a sequenced set of picture prompts. Having collected the data, Pearson correlation coefficient was run to establish the statistical significance of the correlations among the variables. The results displayed that participants' perceived level of second language (L2) writing anxiety is negatively associated with the complexity, accuracy, and fluency of their task-based written output.

Sadiq (2017) explored the level of foreign language anxiety among Arab English language learners. The quantitative research design was used through a survey methodology in order to collect data about the participants' language anxiety. The sample of the study consisted of 100 university students, who were randomly selected, from the college of Education at Princess Nora University in the Kingdom of Saudi Arabia. Foreign Language Classroom Anxiety Scale developed by Horwitz, Horwitz, and Cope (1986) was used to collect the research data. Results revealed that EFL students experience moderate level of anxiety. Results indicate the presence of a meaningful difference in the level of language anxiety among the participants of the study in terms of age variable.

Asif (2017) explored the factors that trigger language anxiety among Saudi learners in English as Foreign Language (EFL) classrooms and the strategies that can be designed and used to cope with language anxiety successfully. The sample of the study consisted of 115 teachersof English at various colleges and universities in Saudi Arabia, who were randomly selected. Results revealed that the main factors which cause anxiety are mainly psycholinguistic and are related to foreign language learning processes, and other factors are socio-cultural and related to Saudi culture and society. Additionally, anxiety was manifested in many different ways among Saudi EFL learners, which include the poor performance in English language learning, making frequent mistakes, and nervousness on the part of the learners during class presentations.

Wahyuni \& Umam (2017)explored the writing anxiety among EFL students at an Islamic State College in Indonesia. The study examined the levels, dominant type, and main factors of writing anxiety among EFL students. The sample of the study consisted of (50) EFL students at the college. Two closed-ended scales were used to collect the data. Results revealed that $54 \%$ of the students showed a high level of writing anxiety, $44 \%$ showed a moderate level, and $2 \%$ showed a low level of writing anxiety. The dominant type of writing anxiety among EFL students was cognitive writing anxiety, which is based on the highest mean among two other types of writing anxiety. Thus, results revealed four main factors related to writing anxiety: linguistic difficulties, fear of teachers' negative comments, insufficient writing practice, and time pressure.

El-Shimi (2017) sought to find out the causes and most common types of second-language writing anxiety among students taking an intensive English course in the English Language Institute (ELI) at the American University in Cairo (AUC). Both quantitative and qualitative research methods were used in this exploratory study. A convenience sample of 51 Egyptian ESL learners enrolled in the Intensive English Program (IEP) in the ELI was chosen to participate in the study. The researcher gave them a questionnaire adapted from the Second Language Writing Anxiety Inventory (SLWAI) developed by Zhang (2011) in order to identify the causes and most common types of writing anxiety among them. To investigate the teachers' perspectives of L2 writing anxiety, interviews with six teachers in the IEP with varying years of teaching experience were conducted. The results of the quantitative data, using descriptive statistics, showed that the most common types of L2 writing anxiety among the students were Somatic Anxiety (SA) and Cognitive Anxiety (CA). On the other hand, a very small percentage of the students suffered from Avoidance Anxiety (AA). The reason why their level of SA and CA were higher is ascribed to the fact that most of their causes of L2 writing anxiety were associated more with physiological and psychological effects resulting from their anxiety experience. The teachers' answers to the interview questions corresponded with the students' responses to the questionnaire items. They reported that they notice and observe symptoms related to L 2 writing anxiety very similar to those indicated by the students.

Jebreil and his colleagues (2015) examined the level of writing anxiety of the Iranian EFL students with different proficiency levels. The sample of the study consisted of 45 students (elementary, intermediate, and advanced learners) who were selected randomly from among the students at Azad University in Iran. Second, Language Writing Anxiety Inventory was used to collect data. Results of the study showed that Iranian EFL students had a high level of anxiety. Additionally, students with elementary level had higher level of English writing anxiety in comparison with the students of intermediate and advanced levels. Results revealed also that cognitive anxiety was the most common type of anxiety among the participants, followed by somatic anxiety, and avoidance behavior. The results showed that foreign and 
second language teachers ought to be cautious of the dangers of anxiety and seek to establish a stress-free class in order to improve students' performance.

Rahim and Hayas (2014) also conducted a study on L2 writing anxiety but from a slightly different angle. They aimed to find out how L2 learners' writing anxiety affects their choice of doing the writing task. The results of the questionnaire they used showed that out of the three types of anxiety (Cognitive Anxiety (CA), Somatic Anxiety (SA), and Avoidance Anxiety (AA), a high percentage of the learners had CA (87 percent), which confirms the results of the study that Shang (2013) conducted. All three types of anxiety, however, did have an impact on learners' choice to do the writing task, as 50 percent of the learners also suffered from a high level of SA and nearly 43 percent of the learners had a high level of AA. Those who suffered from CA and SA chose not to do the writing task itself mainly due to similar reasons like the ones mentioned in other studies such as other people's (teachers and peers) perceptions of their writing. On the other hand, those who suffer from all three types of anxiety to a minimal extent only think of more practices in writing as a way to help them improve their English language writing skill. The quantitative (multiple choice questions on questionnaire) and qualitative (open ended questions) methods used in this study made its results somehow more reliable than other studies.

Choi (2013) investigated the relationship between foreign language anxiety and second language writing anxiety among second language (L2) English learners in Korea and the influence of English writing anxiety on second language writing performance. Data were collected through two survey instruments, which were administered to the participants of the study (26 junior high school EFL students), where the teacher had implemented an innovative writing portfolio assignment. Results showed a significant positive correlation between the FLCAS and the EWAS. No significant correlation was found between EWAS and writing performance as observed in the student portfolios, but students with high EWAS scores did tend to show poor performance on the writing portfolio.

Negari and Rezaabadi (2012) explored the relationship between the students' Writing anxiety and their writing performance in EFL context. The sample of the study consisted of 27 Iranian EFL students, majoring in English translation and English literature, who participated in TOFEL proficiency test. Results suggested that the students experienced less nervousness in writing when the teacher assured them that their papers will not be scored in contrast to the time when their papers were to be scored by the teacher. Results revealed a statistically significant high correlation between final writing test and anxiety. The participants' responses to the open-ended questionnaire revealed that during their first stage of writing experience (when the teacher assured them that their papers will not be scored), the students had less physiological and psychological changes than their final test.

Zhang (2011) examined the predominant type of anxiety among two groups of Chinese learners (49 freshmen and 47 sophomores) majoring in English and different strategies in which they can cope with them. Results revealed a number of causes of ESL writing anxiety among both groups, but the most common ones were linguistic difficulties, insufficient writing practice, fear of tests, and lack of topical knowledge.

In conclusion, most of the studies that focused on L2 writing anxiety sought to identify the causes and the most common types of L2 writing anxiety, but almost none of them explored the correlation between L2 writing anxiety and the grammatical complexity of the written compositions of EFL students in the Jordanian or the Arab context. Consequently, the purpose of this research is to examine the correlation between L2 writing anxiety and the grammatical complexity of the written compositions of EFL students in the Jordanian context.

\section{PROBLEM OF THE STUDY}

L2 learners very often consider writing in a language they are not yet familiar with a very difficult skill. Writing is considered both a cognitive and an emotional activity, where learners reflect and feel while they are writing, and this is why they very often find it difficult. Another possible reason could be the fact that writing requires them to be able to express themselves, maintain a flow of ideas, develop their confidence, and enjoy writing using their L2 (Al-Shimi, 2017). All EFL undergraduate students must be able to know how to write, as nowadays writing is considered a requirement in almost any academic pursuit and is very often related to the extent to which they can succeed in different academic subjects. Most research on FL anxiety has focused mainly on the oral aspects (speaking and listening) of language use. In the last few decades, however, a number of studies have been done on L2 writing anxiety and its effect on $\mathrm{L} 2$ acquisition and achievement.

\section{QUESTIONS OF THE STUDY}

1. Do Jordanian ESL undergraduate students suffer from L2 writing anxiety?

2. Is there a significant correlation between writing anxiety and the use of subordinate clauses in the written compositions of Jordanian EFL students?

\section{STUDY METHOD}

A. Sample of the Study 
Population of the current study consists of BA students of English literature at Al-Balqa Applied University. The sample of the study consisted of 87 B.A students of English literature at Al-Balqa Applied University. Of which 45 students were freshmen and 42 were seniors in the academic year 2017/ 2018.

\section{B. Instrument of the Study}

The Writing Anxiety Inventory (Kassem, 2017) was used in the current study to measure the level of writing anxiety among the Jordanian EFL students at Al-Balqa University during the process of writing compositions in an EFL context. The inventory included (12) items which are answered on a five-point Likert Scale, ranging from 1 (strongly disagree) to 5 (strongly agree). Students with a score of $75 \%$ and higher are assumed to have from a high level of writing anxiety, while the students whose score range from $50 \%$ to $74 \%$ are assumed to experience a moderate level of writing anxiety. Students with score of less than $30 \%$ were assumed to be learners with an acceptable level of writing anxiety. In the first semester of the academic year 2017/2018, the instrument of the study (WAI) was completed by the participants of the sample of the study. Grammatical complexity levels were measured by counting the number of subordinate clauses and finding the average number of subordinate clauses per text for each group.

\section{RESULTS OF THE STUDY}

In order to answer the first question of the study, means and standard deviations of writing anxiety levels among participants were calculated, and table (1) shows the results.

TABLE (1):

MEANS AND STANDARD DEVIATIONS OF WRITING ANXIETY LEVELS AMONG THE PARTICIPANTS OF THE SAMPLE OF THE STUDY:

\begin{tabular}{|l|l|l|l|}
\hline Group & N & Mean & SD \\
\hline Freshmen Students & 45 & 46.41 & $\mathbf{6 . 3 2}$ \\
\hline Senior Students & 42 & $\mathbf{2 7 . 3 2}$ & $\mathbf{4 . 1 2}$ \\
\hline
\end{tabular}

Table (1) shows a higher level of writing anxiety among the participants of the group of freshmen, in comparison with the group of senior students, which agrees with the results of several studies conducted in Arab context of Arab EFL learning, and (Al-Shimi, 2017; Asif, 2017).Zhang (2011) suggested that EFL students, especially those who employ productive skills such as speaking and writing, frequently feel anxious in the learning process. The results of the current study confirm and agree with the results of Zhang despite the differences between the contexts of the two studies.

Concerning the grammatical complexity of the written compositions of the participants of the study sample, the means of the numbers of Subordinate clauses in the texts written by the students were calculated, as well as the maximum and minimum number of subordinate clauses in these texts, and table (2) shows the results.

TABLE (2):

MEANS, MAXIMUM AND MINIMUM NUMBER OF SUBORDINATE CLAUSESOF THE NUMBERS OF SUBORDINATE CLAUSES IN THE TEXTS WRITTEN BY THE STUDENTS

\begin{tabular}{|l|l|l|}
\hline Measure & Freshmen Students & Senior Students \\
\hline Sub. clauses per text & 3.7 & 5.6 \\
\hline Minimum & 0 & 0 \\
\hline Maximum & 8 & 11 \\
\hline
\end{tabular}

On the whole, the freshmen group of EFL students at Al-Balqa University in the sample of the present study yielded a lower level of grammatical complexity in their written texts in English, in comparison to the senior group of EFL students, whose participants had higher scores in the level of grammatical complexity which appeared in their written compositions, i.e. subordination and noun phrase modification. With regard to the average number of subordinate clauses per text, the freshmen group produced less $(m=3.7)$ subordinate clauses compared to the group of senior undergraduate students $(m=5.6)$. these results agrees with the results of previous studies, which showed the tendency of increased subordination as students progress in their study of ESL is confirmed by several studies (Larsen, 2016). Studies (Hunt, 1965; cited in Larsen, 2016) suggest that the ratio of subordinate clauses per T-unit gradually increase as students become older. As the writers became older, they also produced more subordinate clauses. Thus, it is not surprising that Jordanian EFL students increase their use of subordinate clauses as they progress in their study at the university.

Hussein \& Muhammad (2011) indicate that EFL students experience several language proficiency problems while writing in English, which are ascribed to differences between Arabic and English and as a result, students tend to employ various compensatory strategies to solve this problem in that they try to write words and sentences in L1 first and consequently translate them into L2 thus making negative transfer.

In order to examine the significance of the differences between the results of the group of freshman B.A students of English Literature, and the group of senior BA students, ANOVA test was applied, and table (3) shows the results. 
TABLE (3):

ONE-WAY ANALYSIS OF VARIANCE (ANOVA) OF BETWEEN GROUP AND WITHIN GROUP MEANS

\begin{tabular}{|l|l|l|l|l|l|}
\hline & Sum of Squares & Df & Mean Square & F & Sig. \\
\hline Between Groups & 19.267 & 1 & 19.267 & 3.986 & .051 \\
\hline Within Groups & 280.333 & 58 & 4.833 & & \\
\hline Total & 299.600 & 59 & & & \\
\hline
\end{tabular}

Table (3) shows that the difference between the freshman B.A students of English Literature, and their counterparts, the senior B.A students Literature at Al-Balqa university explains about $3.986 \%$ of the variation in the scores of the students, so, the relationship between the variable of writing anxiety and the students' use of subordinate clauses is weak but statistically significant.

Table (3) revealed an F value of 3.986, which with 1 and 58 degrees of freedom is statistically significant at the .000 level $(\mathrm{P}<0.05)$. These figures indicate that the difference across the independent variable category (Freshmen Vs. senior undergraduate students) is significant.

\section{CONCLUSION}

Results of the current study revealed a significant correlation between the level of writing anxiety and the grammatical complexity of the Jordanian university students' written texts. Thus, an inverse proportion exists between writing anxiety and the use of subordination among EFL undergraduate students. Therefore, in order to enhance the grammatical complexity of the EFL students' written texts, writing anxiety ought to be alleviated, which is a difficult task to be undertaken by educators.

The following recommendations for additional future research are offered:

- Replicating the study with a larger number of students, either at a higher education institution in Jordan or any other similar institution in the Arab region.

- Replicating the study with EFL learners whose L1 is a language other than Arabic, and comparing the results with the findings of the current study.

\section{REFERENCES}

[1] Adjei, A., \& Williams, R. (2014). The Handling of Subordinate Clauses by Students of Teacher Training Colleges in Ashanti Region.International Journal of English Language Teaching, 2(3), 37-52.

[2] Asif, F. (2017). The Anxiety Factors among Saudi EFL Learners: A Study from English Language Teachers' Perspective. English Language Teaching, 10(6), 160-173.

[3] Baten, K., \&Håkansson, G. (2015). The Development of Subordinate Clauses in German and Swedish As L2S. Studies in Second Language Acquisition, 37(3), 517-547.

[4] Cheng, Y. (2004). A measure of second language writing anxiety: Scale development and preliminary validation. Journal of Second Language Writing, 13(4), 313-335.

[5] Choi, S. (2013). Language anxiety in second language writing: Is it really a stumbling block? University of Hawai'I Second Language Studies Paper 31 (2), 1-42.

[6] Daly, J., \& Miller, M. (1975).The Empirical Development of an Instrument of Writing Apprehension. Research in the Teaching of English, (9): 242-249.

[7] El-Shimi, E. (2017). Second-language learners' writing anxiety: Types, causes, and teachers' perceptions. Thesis, The American University in Cairo.

[8] Hussein, A., \& Mohammad, M. (2011).Negative L1 impact on L2 writing. International Journal of Humanities and Social Science, l(18), 184-195.

[9] Jebreil, N., Azizifar, A., Gowhary, H., \& Jamalinesari, A. (2015). Study on Writing Anxiety among Iranian EFL Students. International Journal of Applied Linguistics and English Literature, 4(2), 68-72.

[10] Kassem, M. (2017). Developing Business Writing Skills and Reducing Writing Anxiety of EFL Learners through Wikis. English Language Teaching, 10(3), 151-163.

[11] Larsen, L. (2016). Fluency and complexity in the written English of Norwegian 7th graders: A comparative study of pupils in the Early Years Literacy program (EYLP) with those in a textbook-based approach. Thesis, University of Stavanger, Norway.

[12] Negari, G., \&Rezaabadi, O. (2012). Too nervous to write?The relationship between anxiety and EFL writing. Theory and Practice in Language Studies, 2(12), 2578-2586.

[13] Park, J. (2017). Syntactic Complexity as a Predictor of Second Language Writing Proficiency and Writing Quality. Doctoral dissertation, Michigan State University.

[14] Rahim, S. A., \& Hayas, K. M. (2014). Investigating student's second language writing anxiety: a case study. Persidangan MICELT conference, 2014, 13-15 Sept 2014, Hotel Palace of Golden Horses, Kuala Lumpur.

[15] Saeedi, M., \&Farnia, M. (2017). Iranian EFL Learners' Perceived Writing Anxiety and the Complexity, Accuracy, and Fluency of their Task-based Writing: Are they Correlated? Journal of Applied Linguistics and Language Research, 4(8), 68-78.

[16] Wahyuni, S., \& Umam, M. (2017). An Analysis On Writing Anxiety Of Indonesian Efl College Learners. JEELS, 4(1), 105128.

[17] Zhang, H. (2011). A study on ESL writing anxiety among Chinese English majors: Causes, effects and coping strategies for ESL writing anxiety. Kristianstad University Sweden, 1-41. 
Maram Teimeh Atallah Haddad was born on March 13, 1976 in Ajloun, Jordan. She is an instructor of English at Al-Balqa Applied University, Irbid University College Jordan. She had an M.A degree in English Linguistics from Yarmouk University. Her research interests include: General linguistics, Applied Linguistics and first and second language acquisition. 